\title{
ICSI using fresh and frozen PESA-TESA spermatozoa to examine assisted reproductive outcome retrospectively
}

\author{
Aamir Javed', Manjula Kannasandra Ramaiah', Muralidhar Srinivasaih Talkad² \\ ${ }^{1}$ Department of Biotechnology, REVA University; ${ }^{2}$ Post Graduate-Department of Biotechnology, Dayananda Sagar Institutions, Bangalore, India
}

Objective

The male reproductive system generates, accumulates, and transports the sperm. In this study, 2 methods of surgically retrieving sperm, namely, testicular sperm aspiration (TESA) and percutaneous epididymal sperm aspiration (PESA), are discussed and studied in men aged $\leq 38$ years to achieve successful conception using assisted reproductive technology. The purpose was to assess the fertilization rate (FA), clinical pregnancy, and live birth rate (LBR) with sperm.

\section{Methods}

A total of 287 semen samples were divided into 4 groups as follows: fresh PESA ( $n=73)$, frozen PESA ( $n=65)$, fresh TESA $(n=128)$, and frozen TESA ( $n=21)$. The DNA fragmentation test using sperm chromatin dispersion assay was measured and reported.

\section{Results}

FA was $70.3 \%$ and $65.5 \%$, $(P<0.022)$ for fresh and frozen epididymal sperm and $53.8 \%$ and $49.5 \%,(P<0.032)$ for fresh and frozen testicular sperm. LBR was $33.6 \%$ and $30.2 \%(P<0.075)$ for fresh and frozen epididymal sperm (PESA) and $22.7 \%$ and $18.2 \%(P<0.063)$ for fresh and frozen-thawed TESA sperm.

\section{Conclusion}

Exposure to tissue shearing may adversely affect sperm quality. Increased sperm DNA damage due to long-term exposure while teasing enhances reactive oxygen species production foremost to membrane damage because of the oxidation of polyunsaturated fatty acid in lipids (lipid peroxidation), oxidation of amino acid in proteins, and inactivation of specific enzymes, all leading to enzymatic dipping and possibility of less fertilization and conception as indicated by the increase in LBR with fresh/frozen PESA compared to with fresh/frozen TESA.

Keywords: Spermatozoa; Fertilization; Infertility; DNA fragmentation

\section{Introduction}

Assisted reproductive technology (ART) is composed of medical systems used principally to address infertility. The technique has empowered many infertile couples worldwide to have children. ART refers to the in vitro manipulation of eggs, sperm, and embryos to accomplish a pregnancy. It incorporates systems such as in vitro fertilization and intracytoplasmic sperm injection (ICSI) and cryopreservation of gametes or embryos and may also include the utilization of fertility drugs. An additional gratifying technique in andrology is careful spermatozoa recovery for azoospermic patients. Azoospermia is described as nonappearance of spermatozoa in the release $[1,2]$, and it is designated as either obstructive or nonobstructive. Obstructive azoospermia $(\mathrm{OA})$ is the eventual outcome of a blockage in the male reproductive tract; thus, sperm creation in the gonad is normal, and sperm are caught

Received: 2019.03.09. Revised: 2019.06.10. Accepted: 2019.07.09. Corresponding author: Manjula Kannasandra Ramaiah Department of Biotechnology, REVA University, Rukmini Knowledge Park, Kattigenahalli, Yelahanka, Bangalore 560064, India

E-mail: drkrmanjula@gmail.com

https://orcid.org/0000-0002-2011-2662

Articles published in Obstet Gynecol Sci are open-access, distributed under the terms of the Creative Commons Attribution Non-Commercial License (http://creativecommons. org/licenses/by-nc/3.0/) which permits unrestricted non-commercial use, distribution, and reproduction in any medium, provided the original work is properly cited.

Copyright ( 2019 Korean Society of Obstetrics and Gynecology 


\section{Obstetrics \& Gynecology Science}

Vol. 62, No. 6, 2019

inside the epididymis. The nonappearance of sperm in the release can be a direct result of an oddity in the epididymis, vas deferens, or ejaculatory channels. The block brought about by numerous elements such as disease, medical procedure (vasectomies), or a missing vas deferens. Nonobstructive azoospermia (NOA) is the after-effect of seriously impeded or nonexistent spermatogenesis. Approximately $10 \%$ of male-factor barrenness has been attributed to complete azoospermia, which shows either an obstructive or nonobstructive edge [3]. ART predominantly plays a role in the field of regenerative endocrinology and infertility. One of the additionally satisfying methods in male infertility is careful sperm recovery. Thus, reproductive biologists must be inclined to provide couples the best conceivable chance of recovering suitable sperm at the time of spermatozoa recovery [4]. Two reasons can explain the absence of sperm in semen. OA is the delayed consequence of blockage in the male reproductive tract; under this circumstance, sperm are delivered in the gonad but are caught in the epididymis. NOA is the eventual outcome of nonexistent spermatogenesis [5]. Since the introduction of ICSI in the mid-1990s, careful procedures to recoup tests from the epididymis and testis straightforwardly have been used to profit patients with OA and NOA [6].

Two vital accomplishments have been obtained recently in the field of male barrenness [7]: the first is the improvement of the ICSI system for the treatment of male-factor barrenness on account of oligoasthenoteratozoospermia (OAT) semen quality and the second is the development of ICSI for azoospermic patients and demonstration that spermatozoa taken from either the epididymis or testis are fit for normal fertilization and pregnancy [7]. ICSI is currently the essential treatment method for male-factor infertility and for attaining high pregnancy rates in couples with OAT spermatozoa. In broad-spectrum, ejaculation-recovered spermatozoa attained increased fertilization rates (FAs) as compared with percutaneous epididymal sperm aspiration (PESA) and testicular sperm aspiration (TESA) [8]. One concern associated with the utilization of OAT spermatozoa for ICSI is the latency of the transmission of hereditary variations in male infertility to the offspring [9]. In spite of this concern, ICSI has been used as the standard remedial method for these patients in in vitro fertilization (IVF) facilities. Tests using surgically recovered sperm are regularly arranged for use before a patient advances through an ICSI cycle. This is a sheltered strategy in instances of OA. However, in instances of NOA, undergoing the procedure prior to the cycle is favourable because the female partner has already been stimulated with hormones. Epididymal suctions are generally simple to get ready in the laboratory, either for ICSI or for cryopreservation. Generally, an embryologist washes the sample with washing media to remove any epididymal liquid or contamination. The most widely recognized issues are abnormal levels of erythrocytes, absence of sperm, poor sperm motility, and moderate movement [10].

The primary intention of this study was to assess the fertilization rate (FR), clinical pregnancy (CP), and live birth rate (LBR) when fresh and frozen sperm were used, recovered through PESA and TESA, respectively.

1. On account of $O A$ : ordinary follicle-stimulating hormone $(\mathrm{FSH} ;<7 \mathrm{IU} / \mathrm{L})$ and patients with inborn aplasia of the vas deferens.

2. Indicated on account of normogonadotropic infertility (FSH level $<7 \mathrm{IU} / \mathrm{L}$ ) either NOA or hypergonadotropic (FSH level $\geq 7 \mathrm{IU} / \mathrm{L}$ ) azoospermia.

The second condition is weakened spermatogenesis related to central Sertoli-cell-only (SCO) disorder (Table 1).

\section{Materials and methods}

\section{Patient selection criteria}

Like any surgery, patient selection is vital for effective sperm recovery. The patient selection was based on patients with NOA and OA. A total of 138 patients with OA and 149 patients with NOA were admitted. Testosterone ( 4.4 vs. $3.3 \mathrm{ng} / \mathrm{mL}$ ) and E2 ( 25.8 vs. $18.8 \mathrm{pg} / \mathrm{mL}$ ) levels were significantly higher, whereas FSH (5.9 vs. $27.2 \mathrm{mlU} / \mathrm{mL}$ ) and luteinizing hormone levels (3.5 vs. $11.8 \mathrm{mlU} / \mathrm{mL}$ ) were lower in the OA group than in the NOA group. In addition, men with inherent absence of congenital bilateral absence of the vas deferens may require broad investigation of the epididymis, or a few may entail a testicular sperm recovery [11]. The size and uniformity of the testis are vital in the presurgical evaluation. Men with NOA will probably have diminutive testes than men with OA. We additionally prefer to survey the solidness of the epididymis. Men with abnormal FSH levels, testicular size, and discharge volume may have either NOA or OA [12]. In such cases, a testicular excision might be needed to make an authoritative conclusion. Histopathological assessment of testicles demonstrates the nearness of typical spermatogenesis in instances 


\section{Obstetrics \& Gynecology Science}

Aamir Javed, et al. ICSI using fresh and frozen PESA-TESA spermatozoa

of OA, while hypospermatogenesis or development capture or SCO are found in men with NOA. A testicular biopsy might be rejected in instances of increased FSH level and small testicles, as this affiliation is characteristic of NOA [13]. Of 287 ICSI cycles performed, 138 PESA samples, including 73 fresh and 65 frozen-thawed samples, were used for ICSI. Of 149 TESA samples, 128 fresh and 21 frozen-thawed samples were used for the ICSI. Finally, 201 fresh ICSI cycles (128 fresh TESA and 73 fresh PESA samples) were performed, and ICSI procedures with 86 frozen-thawed sperm were performed (21 with frozen-thawed TESA sperm and 65 with frozen-thawed PESA sperm) [14]. The International Committee of Medical Journal Editors guideline and recommendation have been followed diligently [15].

\section{Two strategies for retrieving sperm}

\section{1) Percutaneous epididymal sperm aspiration}

This straightforward procedure can be completed under local anesthesia or mellow sedation. In contrast to microsurgical epididymal sperm aspiration, where the andrologist can picture the revealed epididymal tubules, PESA is an unsighted procedure that can be performed under local anesthesia with oral sedation [16]. A 20-22 G butterfly needle was fixed with a 2.0-mL syringe filled with $1 \mathrm{~mL}$ of sperm wash medium [17]. The needle was passed into the upper scrotum through an anesthetized site. Then, suction was applied using the syringe, and a hemostat was set over the tubing of the butterfly needle to hold the vacuum. While keeping the butterfly needle inside the scrotum, the head of the epididymis was then arranged inside the thumb and forefinger, and the needle was passed into the head of the epididymis [18].
Once entered, the hemostat was released, empowering the vacuum to then move sperm into the tubing [19]. The needle was pushed ahead and in reverse on various occasions without pulling it back from the skin to pull back the maximum amount of sperm into the tubing and syringe [20]. The sperm was put on a slide for analysis by the embryologist. After the needle was pulled back, pressure was guided toward the site to lessen the risk of hematoma [21].

\section{2) Testicular sperm aspiration}

For patients with OA in whom sperm cannot be found in the epididymis, sperm is always expected to be found in the testis. TESA might be performed as an essential collecting procedure if the epididymis or extreme epididymal fibrosis is missing. TESA is normally performed using an $18 \mathrm{G}$ to 1.5-in needle inserted in a $10-\mathrm{mL}$ syringe stacked into a fineneedle aspiration gun and prepared with approximately $1 \mathrm{~mL}$ of sperm wash media [22]. Another method is TESA, which includes using a smaller butterfly needle and hemostat to maintain suction, like in the PESA. After a spermatic cord and skin block are used, the testis becomes immovable and can be handled by the andrologist, with the epididymis kept posteriorly [23]. Enormous caution must be taken to avoid damage to the epididymis during TESA. The scrotal skin is extended tight, and the needle is passed specifically into the focal point of the mid-front testis before the vacuum is maximally made with the gun syringe. Keeping up vacuum suction, the needle is then delicately moved forward and backward in a saw-like example, keeping the needle inside the testicular parenchyma [24]. After roughly 10 passes, the needle is pulled back while paying attention to the suction. Tubules will ideally pursue the needle out, and these tubules

Table 1. Testicular biopsy indications: testicular sperm aspiration (TESA)/percutaneous epididymal sperm aspiration (PESA)

\begin{tabular}{lcccc}
\hline Diagnostic parameter & $\begin{array}{c}\text { Obstructive azoospermia } \\
(\mathbf{n}=\mathbf{1 3 8 / 2 8 7})\end{array}$ & $\begin{array}{c}\text { Non-obstructive } \\
\text { azoospermia }(\mathbf{n}=\mathbf{1 4 9 / 2 8 7})\end{array}$ & Clinical application & P-value \\
\hline Male age (yr) & $35.1 \pm 2.0$ & $38.6 \pm 1.4$ & NA & NA \\
Female age (yr) & $31.5 \pm 4.0$ & $32.5 \pm 5.3$ & TESA/PESA and ICSI & $<0.02$ \\
FSH (IU/L) & $5.9 \pm 1.1$ & $27.2 \pm 2.5$ & TESA/PESA and ICSI & $<0.04$ \\
LH (mlU/L) & $3.5 \pm 0.2$ & $11.8 \pm 0.4$ & TESA/PESA and ICSI & $<0.01$ \\
Testosterone (ng/mL) & $4.4 \pm 1.1$ & $3.3 \pm 0.8$ & TESA/PESA and ICSI & 0.94 \\
Prolactin (mlU/L) & $11.5 \pm 2.2$ & $11.4 \pm 2.1$ & TESA/PESA and ICSI & $<0.01$ \\
E2 (pg/mL) & $25.8 \pm 1.9$ & $18.8 \pm 3.6$ & &
\end{tabular}

Values are presented as mean \pm standard deviation.

FSH, follicle-stimulating hormone; LH, luteinizing hormone; NA, not available; ICSI, intracytoplasmic sperm injection. 


\section{Obstetrics \& Gynecology Science}

Vol. 62, No. 6, 2019

are lifted with forceps and clipped and extracted at the dimension of the skin. The syringe is then expelled from the gun, and the suction is showered into a glass petri dish for the embryologist to survey [25]. At that point, an embryologist looks at the suction for motile or immotile spermatozoa with a stereomicroscope. By using fine needles, sperm are discharged from inside the seminiferous tubules, where sperm are delivered, and they are then dismembered from the encompassing tissue. Next, the embryologist decides if there is an adequate number of sperm for treatment or cryopreservation for later [26]. If not, a few more needle biopsies will be endeavored by the specialist in each testis to acquire an adequate amount. Occasionally, enough tissue is taken for pathologic assessment of a couple of tubules.

\section{Test used}

\section{1) Sperm chromatin dispersion assay}

The sperm chromatin dispersion (SCD) test was performed using the halo sperm kit following the standard protocol. Samples were stained with the standard staining kit, and maximum spermatozoa were examined and identified as fragmented or non-fragmented based on their halo formation following the principle of the SCD test. Fresh whole spermatozoa (fresh or frozen) samples are preferred over frozen ones for better identification of DNA fragmentation. The sample is engrossed in an inert agarose microgel on a pretreated slide. Non-fragmented DNA spermatozoa upon initial treatment with diluted acid denature DNA and, subsequently, upon treatment with lysing solution evacuates most nuclear proteins. In the absence of gigantic DNA, breakage produces nucleoids with outsized radiances of spreading DNA circles, ascending from a focal center and vice versa. Visualization can be performed using bright field microscopy. However, if the staining is too concentrated, the pre-stained slide can be gently washed with tap water [27]. From the test performed, the fraction of the SCD assay result shows that the average percentage of dispersion was $63.76 \%$ for the fresh PESA samples and $56.99 \%$ for the frozen PESA samples (Fig. 1). Similarly, the average percentage of non-dispersion was $36.23 \%$ for the fresh PESA and $43.00 \%$ for the frozen PESA. Likewise, the dispersion percentage was $38.00 \%$ for the fresh TESA and $32.81 \%$ for the frozen TESA (Table 2).

\section{Statistical analysis}

Data were expressed as mean \pm standard deviation. Continuous variables were analyzed using the Student's $t$-test. The diagnostic parameters, FR, and LBR were evaluated. Differences with $P$-values of $<0.05$ were considered statistically significant.

\section{Results}

The FRs (per injected metaphase-2 oocytes) after ICSI measured using the Narishige micromanipulator (Narishige, To-

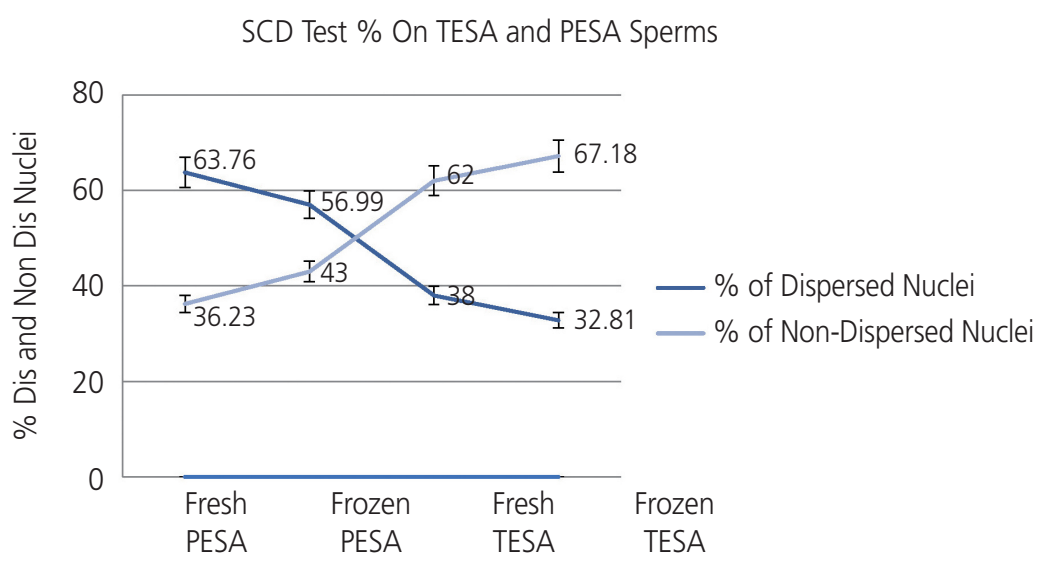

Fig. 1. Sperm chromatin dispersion (SCD) test \% on testicular sperm aspiration (TESA) and percutaneous epididymal sperm aspiration (PESA) sperms. Data presented as dispersed and non dispersed nuclei mean percentage for the 4 independent observations, dispersed and non-dispersed percentage for fresh PESA (63.76-36.23), dispersed and non-dispersed percentage for frozen PESA (56.99-43), dispersed and non-dispersed percentage for fresh TESA (62-38) and dispersed and non-dispersed percentage for frozen TESA (67.18-32.81) and number of observation in fresh PESA $=73$, frozen $P E S A=65$, fresh TESA $=128$, and frozen TESA $=21$. 


\section{Obstetrics \& Gynecology Science}

Aamir Javed, et al. ICSI using fresh and frozen PESA-TESA spermatozoa

kyo, Japan) were $70.3 \%, 53.8 \%, 65.5 \%$, and $49.5 \%$ using fresh epididymal sperm, fresh testicular sperm, frozen PESA, and frozen TESA, respectively (Table 3 ). The CP rate was 36.5\% for fresh PESA and 34.6\% for frozen-thawed PESA sperm. Subsequently, the clinical pregnancy rate was $29.2 \%$ for fresh testicular sperm and $24.3 \%$ for frozen-thawed sam- ples [1] (Table 4). Finally, the LBR per embryo transfer (embryo transfer catheters used: Labotect Catheters and Cooks Sydney IVF Catheter 6019) was 33.6\% for fresh epididymal sperm (PESA) and $30.2 \%$ for frozen-thawed PESA sperm and $22.7 \%$ for fresh TESA and $18.2 \%$ for frozen-thawed TESA (Fig. 2).

Table 2. Sperm DNA fragmentation halo test values for fresh and frozen percutaneous epididymal sperm aspiration (PESA)-testicular sperm aspiration (TESA)

\begin{tabular}{|c|c|c|c|c|c|}
\hline Test: sperm chromatin dispersion & Fresh PESA & Frozen PESA & Fresh TESA & Frozen TESA & $\begin{array}{l}\text { Min-sperm } \\
\text { counted }\end{array}$ \\
\hline Average $\%$ of dispersed nuclei & 63.76 & 56.99 & 38.00 & 32.81 & $75-150$ \\
\hline Average $\%$ of non-dispersed nuclei & 36.23 & 43.00 & 62.00 & 67.18 & $75-150$ \\
\hline Sample count & 73 & 65 & 128 & 21 & 287 \\
\hline Large halo & $73.02 \pm 2.04$ & $65.22 \pm 1.55$ & $55.88 \pm 4.04$ & $33.02 \pm 6.02$ & - \\
\hline Medium halo & $69.33 \pm 1.05$ & $52.22 \pm 2.25$ & $45.86 \pm 5.23$ & $29.22 \pm 3.22$ & - \\
\hline Very small halo & $24.23 \pm 2.36$ & $22.02 \pm 0.95$ & $33.56 \pm 2.33$ & $15.89 \pm 1.26$ & - \\
\hline No halo & $0.00 \pm 0.00$ & $2.22 \pm 0.22$ & $0.00 \pm 0.00$ & $5.08 \pm 0.02$ & - \\
\hline$P$-value & \multicolumn{2}{|c|}{$<0.042$} & \multicolumn{2}{|c|}{$<0.028$} & - \\
\hline
\end{tabular}

Data presented as mean percentage (\%) from 4 independent observations (number of observation in fresh PESA=73, frozen PESA=65, fresh $T E S A=128$ and frozen TESA=21 in each 4. Halo representation is in (mean \pm standard deviation) and significance:P<0.05.

Table 3. Fertilization and embryo transfer outcome: testicular sperm aspiration (TESA) and percutaneous epididymal sperm aspiration (PESA)

\begin{tabular}{lccccc}
\hline $\begin{array}{c}\text { Sperm aspiration } \\
\text { method }\end{array}$ & No. of patients & $\begin{array}{c}\text { No. of mature } \\
\text { oocytes }\end{array}$ & $\begin{array}{c}\text { Fertilization } \\
\text { rate }\end{array}$ & $\begin{array}{c}\text { No. of transferred } \\
\text { embryos }\end{array}$ & $\begin{array}{c}\boldsymbol{P} \text {-value: fertilization } \\
\text { rate }\end{array}$ \\
\hline Fresh PESA & 73 & 613 & $431(70.3)$ & 204 & $<0.022$ \\
Frozen PESA & 65 & 474 & $311(65.5)$ & 195 & $<0.032$ \\
Fresh TESA & 128 & 886 & $477(53.8)$ & 307 & 54 \\
Frozen TESA & 21 & 156 & $77(49.5)$ & & \\
\hline
\end{tabular}

Data presented number of fertilization rate and number of embryos transferred, fertilization rate $P$-value fresh and frozen PESA $(P<0.022)$ and for fresh and frozen TESA $(P<0.032)$ for the 4 independent observations. Significance: $P<0.05$.

Table 4. Pregnancy outcome: testicular sperm aspiration (TESA) and percutaneous epididymal sperm aspiration (PESA)

\begin{tabular}{|c|c|c|c|c|c|c|c|c|}
\hline $\begin{array}{l}\text { Sperm } \\
\text { aspiration } \\
\text { method }\end{array}$ & $\begin{array}{l}\text { No. of embryos trans- } \\
\text { ferred (mean } \pm \text { standard } \\
\text { deviation) }\end{array}$ & $\begin{array}{c}\text { Positive } \\
\text { B-hCG (\%) }\end{array}$ & $\begin{array}{l}\text { Embryo } \\
\text { grade A } \\
(\%)\end{array}$ & $\begin{array}{c}\text { Embryo } \\
\text { grade } B+C \\
(\%)\end{array}$ & $\begin{array}{l}\text { Clinical } \\
\text { pregnancy } \\
\text { rate }\end{array}$ & $\begin{array}{l}\text { Miscarriage } \\
\text { rate }\end{array}$ & LBR & $\begin{array}{c}\text { P-value: } \\
\text { LBR }\end{array}$ \\
\hline Fresh PESA & $2.3 \pm 1.2$ & 39.6 & 72.2 & 27.8 & 36.5 & 2.9 & 33.6 & $<0.075$ \\
\hline Frozen PESA & $2.1 \pm 1.4$ & 36.5 & 69.2 & 30.8 & 34.6 & 4.4 & 30.2 & \\
\hline Fresh TESA & $2.4 \pm 1.5$ & 33.7 & 74.6 & 25.4 & 29.2 & 6.5 & 22.7 & $<0.063$ \\
\hline Frozen TESA & $2.2 \pm 1.1$ & 26.8 & 71.4 & 28.6 & 24.3 & 6.1 & 18.2 & \\
\hline
\end{tabular}

Data presented of clinical pregnancy rate and LBR, $P$-value PESA-LBR $(P=0.075$ and for TESA-LBR $(P=0.063)$ for the 4 independent observations. Significance: $P<0.05$.

LBR, live birth rate; hCG, human chorionic gonadotropin. 


\title{
Obstetrics \& Gynecology Science
}

\author{
Vol. 62, No. 6, 2019
}

\section{Discussion}

Sperm maturation advances in the proximal epididymis (corpus epididymis) whereby spermatozoa accomplish their inclination to impregnate eggs and are communicated to sperm aligned with numerous biochemical, physiological, and morphological changes in the spermatozoa $[28,29]$. Laboratory experiments with humans have repeatedly shown that exposure to tissue shearing adversely affects sperm quality [30]. Increased sperm DNA damage due to long-term exposure while teasing enhances reactive oxygen species production foremost to membrane damage because of the oxidation of polyunsaturated fatty acid in lipids (lipid peroxidation), oxidation of amino acid in proteins, and inactivation of a specific enzyme, which all lead to enzymatic dipping, which decreases the possibility of fertilization [31]. Low levels of DNA repair and integrity have pronounced impacts on the reproductive potential and fertilization outcome [32]. Although the FR was affected but not radically by the source of the sperm cells, pregnancy rate and LBR were extensively decreased when fresh and frozen PESATTESA sperm were used.

1. By comparing the outcomes of fresh and frozen spermatozoa used in the ICSI procedures, we conclude that TESA sperm are less vigorous than PESA sperm.

2. According to Pasqualotto et al. [33] is less ready to help in embryonic advancement after reduced fertilization, which is contrary to the results of the study of Qiu et al. [25,26], in which testicular sperm showed higher potential than epididymal sperm.
3. The subjective reason can be that spermatozoa in the PESA are from the epididymal region, which indicates that the spermatozoa are more stable because nuclear maturity is attained, nuclear chromatin protamine condensation is robust, membrane integrity is accomplished, and finally DNA damage is reduced.

However, for the TESA sample, the isolation of the spermatozoa or sperm cells from the seminiferous tubule (testis) sample includes the process of tissue shearing, which in turn helps in identifying the spermatozoa or sperm cell for the procedure. Tissue shearing for the procurement of sperm cells sometimes damages sperm cells, which may activate numerous functions in the cell owing to the vast number of damages because of cell membrane damage that renders the permeability and lead to leakage of cell contents; their hydrophobicity enables them to absorb media [34]. However, men who require TESA samples are likely to have NOA with small or undersized testicles and high FSH levels and develop total testicular malfunction. Thus, we propose freezing spermatozoa recovered from the TESA as reinforcement for future treatment $[35,36]$.

Data obtained in this study did not reveal statistically significant differences in the factors examined between fresh/ frozen PESA and TESA. However, a non-significant inclination favoring maximum $C P$ rate, LBR, and lowest miscarriage rates were observed in fresh PESA as compared with the other 3 parameters. However, miscarriage rates between the fresh and frozen TESA were almost similar, with a percentage variation of only $0.5 \%$ and a difference in the increase in LBR

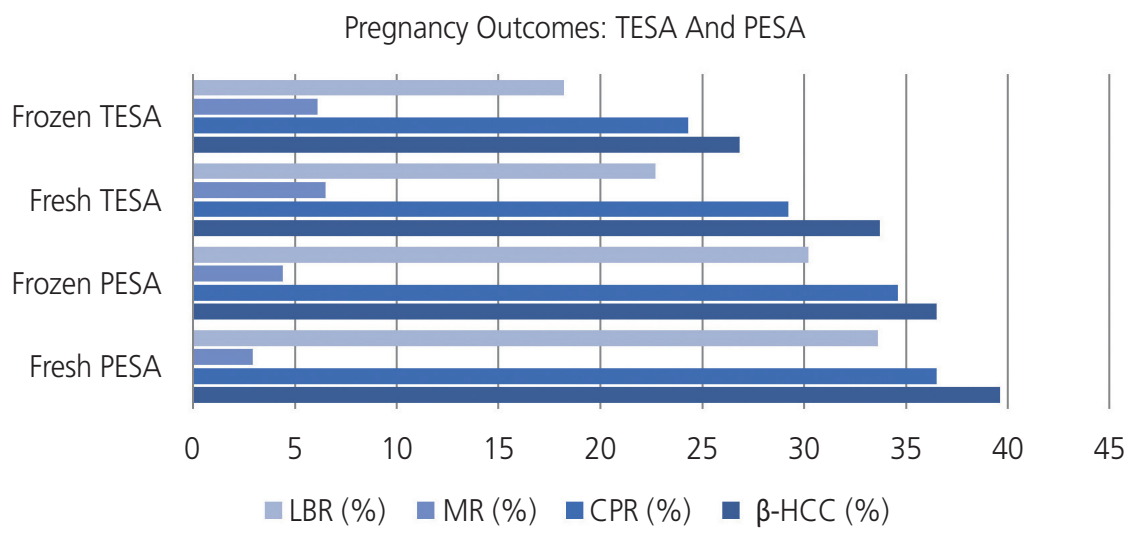

Fig. 2. Pregnancy outcomes: testicular sperm aspiration (TESA) and percutaneous epididymal sperm aspiration (PESA). Data presented as positive $B-h C G(+\beta h c g)$ and clinical pregnancy rate (CPR) mean percentage for the 4 independent observations, $+\beta$ hcg and CPR \& live birth rate (LBR) and miscarriage rate (MR) for fresh PESA (39.6-36.5) \& (33.6-2.9), frozen PESA (36.5-34.6) \& (30.2-4.4), fresh TESA (33.7-29.2) \& (22.7-6.5) and frozen TESA (26.8-24.3) \& (18.2-6.1). 


\section{Obstetrics \& Gynecology Science}

Aamir Javed, et al. ICSI using fresh and frozen PESA-TESA spermatozoa

in fresh TESA [37]. Therefore, further study with a large population size must be conducted to achieve statistically significant results.Progressively complex systems that are useful for making more-precise decisions on central spermatogenesis during medical procedures will enhance this viewpoint. Concerning the laboratory stage, the utilization of programmed or automatic noninvasive sperm retrieval procedures for collected samples may later amplify sperm recovery rates while shortening the seeking period. At whatever point sperm are recovered, novel techniques for sperm choice may enhance the result of ICSI.TESA and PESA samples cannot be used for the conventional IVF procedure. From a clinical perspective, maturation arrest at the round spermatid level is an uncommon phenomenon, occurring only in $0.9 \%$ of NOA men [37]. Birth of $<20$ newborns after round spermatid injection has been reported worldwide.

\section{Acknowledgements}

The authors are thankful to the board of Directors of Base Fertility Medical Sciences Private Limited (BFMSPL), Havanur Circle, Bangalore 560079, India, and R\&I Council, REVA University, Yelahanka, Bangalore 560064, India, for their colossal guidance and support for this project.

\section{Conflict of interest}

No potential conflict of interest relevant to this article was reported.

\section{Ethics approval}

Base Fertility Medical Sciences Private Limited (BFMSPL) approval reference number: BF/EL/IVF/RL/05092014/APR. The study protocol was approved by the institutional review board of BFMSPL.

\section{Patient consent}

All the patients provided informed consent for their data to be used in this study.

\section{References}

1. Temple-Smith PD, Southwick GJ, Yates CA, Trounson $A O$, de Kretser DM. Human pregnancy by in vitro fertilization (IVF) using sperm aspirated from the epididymis. J In Vitro Fert Embryo Transf 1985;2:119-22.

2. Corea M, Campagnone J, Sigman M. The diagnosis of azoospermia depends on the force of centrifugation. Fertil Steril 2005;83:920-2.

3. Esteves SC, Lee W, Benjamin DJ, Seol B, Verza S Jr, Agarwal A. Reproductive potential of men with obstructive azoospermia undergoing percutaneous sperm retrieval and intracytoplasmic sperm injection according to the cause of obstruction. J Urol 2013;189:232-7.

4. Glina S, Fragoso JB, Martins FG, Soares JB, Galuppo AG, Wonchockier R. Percutaneous epididymal sperm aspiration (PESA) in men with obstructive azoospermia. Int Braz J Urol 2003;29:141-5.

5. Hao L, Li ZG, He HG, Zhang ZG, Zhang JJ, Dong Y, et al. Application of percutaneous epididymal sperm aspiration in azoospermia. Eur Rev Med Pharmacol Sci 2017;21:1032-5.

6. Kovac JR, Lehmann KJ, Fischer MA. A single-center study examining the outcomes of percutaneous epididymal sperm aspiration in the treatment of obstructive azoospermia. Urol Ann 2014;6:41-5.

7. Gardner DK, Lane M, Watson AJ. A laboratory guide to the mammalian embryo. New York (NY): Oxford University Press; 2004.

8. Gardner DK, Rizk BR, Falcone T. Human assisted reproductive technology: future trends in laboratory and clinical practice. Cambridge: Cambridge University Press; 2011.

9. Nagy Z, Liu J, Cecile J, Silber S, Devroey P, Van Steirteghem A. Using ejaculated, fresh, and frozen-thawed epididymal and testicular spermatozoa gives rise to comparable results after intracytoplasmic sperm injection. Fertil Steril 1995;63:808-15.

10. Zhu J, Tsirigotis M, Pelekanos M, Craft I. In-vitro maturation of human testicular spermatozoa. Hum Reprod 1996;11:231-2.

11. Smith RP, Coward RM, Lipshultz LI. The office visit. Urol Clin North Am 2014;41:19-37.

12. McBride JA, Coward RM. Recovery of spermatogenesis following testosterone replacement therapy or anabolic- 


\section{Obstetrics \& Gynecology Science}

Vol. 62, No. 6, 2019

androgenic steroid use. Asian J Androl 2016;18:373-80.

13. Coward RM, Mata DA, Smith RP, Kovac JR, Lipshultz LI. Vasectomy reversal outcomes in men previously on testosterone supplementation therapy. Urology 2014;84:1335-41.

14. Boorjian S, Lipkin M, Goldstein M. The impact of obstructive interval and sperm granuloma on outcome of vasectomy reversal. J Urol 2004;171:304-6.

15. International Committee of Medical Journal Editors (ICMJE). Recommendations for the conduct, reporting, editing, and publication of scholarly work in medical journals (December 16, 2014). [place unknown]: ICMJE; 2014.

16. Coward RM, Mills JN. A step-by-step guide to officebased sperm retrieval for obstructive azoospermia. Transl Androl Urol 2017:6:730-44.

17. Gorgy A, Meniru Gl, Naumann N, Beski S, Bates S, Craft IL. The efficacy of local anaesthesia for percutaneous epididymal sperm aspiration and testicular sperm aspiration. Hum Reprod 1998;13:646-50.

18. Donoso P, Tournaye H, Devroey P. Which is the best sperm retrieval technique for non-obstructive azoospermia? A systematic review. Hum Reprod Update. 2007;13:539-49.

19. Van Peperstraten A, Proctor ML, Johnson NP, Philipson G. Techniques for surgical retrieval of sperm prior to intracytoplasmic sperm injection (ICSI) for azoospermia. Cochrane Database Syst Rev 2008;2:CD002807.

20. Bernie AM, Mata DA, Ramasamy R, Schlegel PN. Comparison of microdissection testicular sperm extraction, conventional testicular sperm extraction, and testicular sperm aspiration for nonobstructive azoospermia: a systematic review and meta-analysis. Fertil Steril 2015;104:1099-103.

21. Semião-Francisco L, Braga DP, Figueira Rde C, Madaschi C, Pasqualotto FF, laconelli A Jr, Borges E Jr. Assisted reproductive technology outcomes in azoospermic men: 10 years of experience with surgical sperm retrieval, Aging Male 2010;13:44-50.

22. Lewin A, Weiss DB, Friedler S, Ben-Shachar I, Porat-Katz $A$, Meirow $D$, et al. Delivery following intracytoplasmic injection of mature sperm cells recovered by testicular fine needle aspiration in a case of hypergonadotropic azoospermia due to maturation arrest. Hum Reprod 1996;11:769-71.
23. Gorgy A, Podsiadly BT, Bates S, Craft IL. Testicular sperm aspiration (TESA): the appropriate technique. Hum Reprod 1998;13:1111-3.

24. Jensen $C F$, Ohl DA, Hiner MR, Fode M, Shah T, Smith $\mathrm{GD}$, et al. Multiple needle-pass percutaneous testicular sperm aspiration as first-line treatment in azoospermic men. Andrology 2016;4:257-62.

25. Qiu Y, Wang S, Yang D, Fan Y, Su Q, Wang Z, et al. Percutaneous vasal sperm aspiration and intrauterine insemination in the treatment of obstructive azoospermia. Fertil Steril 1997;68:1135-8.

26. Qiu Y, Wang SM, Yang DT, Wang LG. Percutaneous vasal sperm aspiration and intrauterine insemination for infertile males with anejaculation. Fertil Steril 2003;79:61820.

27. Fernández JL, Muriel L, Goyanes V, Segrelles E, Gosálvez J, Enciso $M$, et al. Simple determination of human sperm DNA fragmentation with an improved sperm chromatin dispersion test. Fertil Steril 2005;84:833-42.

28. Lewin A, Reubinoff $B$, Porat-Katz A, Weiss D, Eisenberg $V$, Arbel $R$, et al. Testicular fine needle aspiration: the alternative method for sperm retrieval in non-obstructive azoospermia. Hum Reprod 1999;14:1785-90.

29. McLachlan RI, Rajpert-De Meyts E, Hoei-Hansen CE, de Kretser DM, Skakkebaek NE. Histological evaluation of the human testis--approaches to optimizing the clinical value of the assessment: mini review. Hum Reprod 2007;22:2-16.

30. Esteves SC, Varghese AC. Laboratory handling of epididymal and testicular spermatozoa: what can be done to improve sperm injections outcome. J Hum Reprod Sci 2012;5:233-43.

31. Schiff JD, Palermo GD, Veeck LL, Goldstein M, Rosenwaks Z, Schlegel PN. Success of testicular sperm extraction [corrected] and intracytoplasmic sperm injection in men with Klinefelter syndrome. J Clin Endocrinol Metab 2005;90:6263-7.

32. Sharpe RM, McKinnell C, Kivlin C, Fisher S. Proliferation and functional maturation of Sertoli cells, and their relevance to disorders of testis function in adulthood. Reproduction 2003;125:769-84.

33. Pasqualotto FF, Rossi-Ferragut LM, Rocha CC, laconelli A Jr, Borges E Jr. Outcome of in vitro fertilization and intracytoplasmic injection of epididymal and testicular sperm obtained from patients with obstructive and non- 


\section{Obstetrics \& Gynecology Science}

Aamir Javed, et al. ICSI using fresh and frozen PESA-TESA spermatozoa

obstructive azoospermia. J Urol 2002;167:1753-6.

34. Ou L, Guo YH, Sun YP, Su YC. Outcomes of ICSI with microamount frozen-thawed sperm obtained by PESA or TESA in the treatment of azoospermia. Zhonghua Nan Ke Xue 2010;16:328-32.

35. Silber SJ, Van Steirteghem AC, Liu J, Nagy Z, Tournaye $H$, Devroey P. High fertilization and pregnancy rate after intracytoplasmic sperm injection with spermatozoa obtained from testicle biopsy. Hum Reprod 1995;10:148-52.
36. Aamir J, Ashwini LS, Ganguly D, Murugan S, Muthiah SS, et al. Interpretation: real-time assessment on immotile but viable spermatozoa for intracytoplasmic sperm injection (ICSI): an embryologists outlook. Austin J In Vitro Fertili 2015;2:1021.

37. Verheyen G, Popovic-Todorovic B, Tournaye H. Processing and selection of surgically-retrieved sperm for ICSI: a review. Basic Clin Androl 2017;27:6. 